\title{
Home monitoring program reduces interstage mortality after the modified Norwood procedure
}

\author{
Stephanie L. Siehr, MD, ${ }^{a}$ Jana K. Norris, NP, ${ }^{a}$ Julie A. Bushnell, NP, ${ }^{a}$ Chandra Ramamoorthy, MD, \\ V. Mohan Reddy, MD, ${ }^{\mathrm{c}}$ Frank L. Hanley, MD, ${ }^{\mathrm{c}}$ and Gail E. Wright, $\mathrm{MD}^{\mathrm{a}}$
}

Background: From 2002 to 2005 , the interstage mortality after a modified Norwood procedure was $7 \%$ in our
program. An interstage home monitoring program (HMP) was established to identify Norwood procedure
patients at increased risk of decompensation and to reduce interstage mortality.

\begin{abstract}
Methods: Results of the first 5 years of the Norwood HMP were reviewed retrospectively. Interstage was defined as the time between Norwood hospital discharge and admission for second stage surgical palliation. In the HMP, families documented oxygen saturation, heart rate, weight, and feedings daily. Nurse practitioners called each family at least weekly, and when issues arose, action plans were determined based on symptom severity.
\end{abstract}

Results: Between October 2005 and October 2010 there were 46 Norwood procedure patients who survived to hospital discharge. All were enrolled in the HMP. Forty-five patients had a Norwood procedure with right ventricle to pulmonary artery conduit, and 1 patient had a modified Blalock-Taussig shunt. Interstage survival was $100 \%$. Nineteen patients $(41 \%)$ were admitted interstage; 5 patients were admitted twice, 1 patient was admitted 4 times. Seventeen patients $(37 \%)$ required interstage interventions. Eight patients (17\%) required major interventions: conduit stenting, aortic arch balloon angioplasty, emergent shunt, or early Glenn surgery. Minor interventions included supplemental oxygen, blood transfusion, intravenous hydration, diuresis, anti-arrhythmic therapy, or feeding adjustments.

Conclusions: In the first 5 years of the HMP, all infants discharged after a modified Norwood procedure survived the interstage period. The HMP altered clinical management in $37 \%$ of patients. Home monitoring of oxygen saturation, heart rate, weight, and feedings, along with comprehensive care coordination, allowed timely interventions and reduced interstage mortality from 7\% to 0\%. (J Thorac Cardiovasc Surg 2014;147:718-23)

Supplemental material is available online.

By the late 1990s, early surgical survival from the Norwood procedure for single-ventricle palliation reached $90 \%$ at major centers, but interstage mortality after the Norwood procedure with modified Blalock-Taussig shunt (mBTS) remained at $7 \%$ to $15 \% .^{1-4}$ Although sudden interstage deaths were a recognized phenomenon, no risk factors had been identified. ${ }^{5-7}$ Proponents of the right ventricle to pulmonary artery (RV-PA) conduit modification theorized that this type of Norwood procedure might have lower interstage mortality because there is no diastolic runoff with a potential coronary steal. ${ }^{8,9}$ However, in our series

\footnotetext{
From the Division of Pediatric Cardiology, ${ }^{\mathrm{a}}$ Department of Pediatrics, Department of Anesthesia, ${ }^{b}$ and Division of Pediatric Cardiac Surgery, ${ }^{c}$ Department of Cardiothoracic Surgery, Stanford University School of Medicine, Palo Alto, Calif.

Disclosures: Authors have nothing to disclose with regard to commercial support.

Received for publication Oct 30, 2012; revisions received March 3, 2013; accepted for publication April 3, 2013; available ahead of print May 10, 2013.

Address for reprints: Gail E. Wright, MD, Division of Pediatric Cardiology, 750

Welch Rd, Suite 325, Palo Alto, CA 94304 (E-mail: gewright@stanford.edu).

0022-5223/\$36.00

Copyright (c) 2014 by The American Association for Thoracic Surgery

http://dx.doi.org/10.1016/j.jtcvs.2013.04.006
}

from 2002 to 2005, which was the largest series of RV-PA conduit Norwood procedures performed at that time, there was $7 \%$ interstage mortality. ${ }^{10}$ It was unclear at the time whether the 7\% interstage mortality represented a true improvement in comparison with the mBTS Norwood procedure results or simply was within the previously reported ranges. Subsequent larger series from several institutions, which directly compared outcomes based on shunt types, have found no significant difference in interstage survival. ${ }^{11-14}$ In the Single Ventricle Reconstruction Trial, the mortality at 30 days after the Norwood procedure to stage 2 surgery was $12 \%$ for RV-PA conduit Norwood patients and $22 \%$ for mBTS Norwood patients. ${ }^{15}$

In 2003, Ghanayem et al ${ }^{16}$ published the results of an interstage home monitoring program for patients after undergoing the Norwood procedure with mBTS. All 36 infants enrolled in the first 2 years survived the interstage period. A majority of those patients were re-admitted to the hospital during the interstage period based on concerning home monitoring trends and required interstage intervention. In theory, the home monitoring program (HMP) allows early detection of physiologic changes that put infants at risk of decompensation, although no specific risk factors were identified. The HMP also detected plateaus in growth, which were interpreted as indicators of insufficient 

Abbreviations and Acronyms
HMP = home monitoring program
LPCH $=$ Lucile Packard Children's Hospital
mBTS $=$ modified Blalock-Taussig shunt
$\mathrm{NG}=$ nasogastric
$\mathrm{NP}=$ nurse practitioner
$\mathrm{RV}-\mathrm{PA}=$ right ventricle to pulmonary artery

metabolic reserve in shunt circulation and guided timing of stage 2 surgery. ${ }^{17}$

Based on that report and our own findings of interstage mortality in RV-PA conduit Norwood patients, we implemented an interstage HMP for Norwood procedure patients in 2005 . The primary goal was to reduce interstage mortality rates. The hypothesis was that alterations in oxygen saturations, failure to gain weight, or acute weight loss as a result of dehydration may be signs of serious anatomic lesions or other physiologic stressors and that early detection would permit life-saving intervention. This article presents results from 5 years of interstage home monitoring in modified Norwood procedure patients with the RV-PA conduit at the Lucile Packard Children's Hospital (LPCH), with specific attention to interstage mortality and interventions to improve survival.

\section{METHODS}

This retrospective, single-institution review was approved by the Institutional Review Board of the Stanford University School of Medicine. All Norwood procedure patient information was extracted from the $\mathrm{LPCH}$ electronic medical record, which included HMP correspondence and data.

\section{Home Monitoring Program Methods and Resources}

The Norwood HMP was established on October 1, 2005, and modeled after the program at the Children's Hospital of Wisconsin. ${ }^{16,18}$

Infants with hypoplastic left heart syndrome or other single-ventricle lesions with significant aortic arch obstruction requiring a Norwood procedure were included in the HMP if they survived to hospital discharge, irrespective of location of outpatient cardiologist follow-up evaluation, proximity to $\mathrm{LPCH}$, or primary language of the family. There was $100 \%$ enrollment of eligible Norwood procedure patients.

Figure 1 summarizes the key components of the HMP. Patient identification and HMP teaching with the family began in the cardiovascular intensive care unit shortly after a Norwood procedure patient was extubated. Each family received a Norwood Procedure Binder consisting of an explanation of the HMP, diagram of Norwood anatomy, red flag indicators, important phone numbers, information for emergency medical providers, and documentation sheets for daily entries. Red flag indicators are signs or symptoms that, if present, should prompt an immediate call to the cardiologist or the HMP nurse practitioner (NP); these included oxygen saturation less than $75 \%$, weight loss of $30 \mathrm{~g}$ or more over a 2- to 3-day span or lack of a 10 - to 20 -g weight gain over 3 days, respiratory distress, or fussiness. Patients were discharged with a pulse oximeter and a digital scale. Several processes were put into place before discharge to optimize care coordination and continuity. A cardiac catheterization to assess Glenn surgical candidacy was scheduled at the patient's 3-month birthday, regardless of the patient's age at Norwood discharge. The majority of these catheterizations were performed at $\mathrm{LPCH}$, but this occurred at the discretion of the referring cardiologist. A surgical date for the Glenn surgery also was scheduled, but that date often was adjusted based on the patient's status during the interstage period or the results of the catheterization. The primary NP spoke directly with the pediatrician, and the HMP cardiologist communicated directly with the outpatient cardiologist just before hospital discharge.

Throughout the interstage period, the parents recorded heart rate, oxygen saturation, weight, and enteral intake once daily. Parents were prompted to call if they noted any red flags, changes in trends of surveillance data, or any symptoms they found atypical or concerning. Emphasis was placed on trends and on a low threshold for calling the NP, rather than single data points. Weekly phone calls from a primary NP tracked changes in clinical status. Information from these calls was used in conjunction with assessments by the primary cardiologist and pediatrician to adjust the medical and nutritional regimen. Frequently, the HMP NP advanced the feedings between clinic visits. When there were clinical concerns, either from the parent or from the care team, or red flag criteria, an action plan was created Depending on the severity of the clinical concern, either HMP call frequency was increased or the patient was seen by a clinician. Patients were seen if there were true red flags, concern for new infection, fussiness, or increased emesis with respiratory symptoms. This visit may have been with the primary cardiologist or pediatrician, in the local Emergency Department, or in the LPCH Emergency Department. Overall, clinical concerns were presumed to be cardiac in nature until proven otherwise, and there was a low threshold to have the patient seen whenever issues arose throughout the interstage period. The only concerns that were addressed solely with increased HMP call frequency were marginal weight gain, slight weight loss with no other symptoms, or minor changes in frequency of vomiting in patients with known reflux.

The HMP multidisciplinary team consists of cardiology NPs, a nurse case manager, a nutritionist, and a single supporting cardiologist (G.E.W.). At implementation, all of the personnel came from existing resources within the Division of Pediatric Cardiology at LPCH. Over time, some administrative time was needed for team communication, equipment ordering, and program maintenance. Pulse oximeters were provided by suppliers of durable medical equipment and for the most part were paid for by the patient's insurance after the HMP team submitted a letter of medical necessity. Scales were paid for with charitable donations and were returned by each family and used serially.

The patients received follow-up evaluation either with a community cardiologist alone (for those who lived remotely), with a primary cardiologist at LPCH (internal patients), or primary follow-up evaluation with the community cardiologist and at least one interstage visit with the HMP cardiologist at LPCH (regional patients). Throughout the interstage period, there was frequent direct communication between the HMP team and community cardiologists and pediatricians. Although families were encouraged to call their primary cardiologist first about concerns (particularly if they lived far from LPCH), many parents seemed to have a lower threshold for calling the HMP NPs. In some cases, the primary care provider was involved integrally, and in other scenarios the majority of the communication was between the HMP team and the primary cardiologist. The basic communication algorithm is summarized in Figure E1. There were many effective variations to this algorithm, but the emphasis was always on very close, direct communication between the family, the HMP team, the primary cardiologist, and the pediatrician. This communication was streamlined, but there also was intentional overlap designed to provide the family constant access to a provider familiar with their infant.

\section{RESULTS}

During the first 5 years of the HMP from October 2005 to October 2010, there were 46 infants enrolled. All eligible patients who survived to hospital discharge after the modified Norwood procedure were enrolled. Interstage survival 


\begin{tabular}{|c|c|}
\hline \multicolumn{2}{|r|}{ Inpatient } \\
\hline $\begin{array}{l}\text { Early Identification and } \\
\text { Preparation for HMP }\end{array}$ & $\begin{array}{l}\text { - HMP Cardiologist identifies eligible patient } \\
\text { - Order equipment } \\
\text { - Assign primary NP/PA, with language fluency } \\
\text { - Teaching- "Norwood binder" } \\
\text { - Begins in CVICU around time of extubation }\end{array}$ \\
\hline Care Coordination & $\begin{array}{l}\text { - HMP has direct communication with PCARD \& PMD } \\
\text { and sets up follow up appointments } \\
\text { - Schedule pre-Glenn cath at } 3 \text { months of age } \\
\text { - Date set before discharge } \\
\text { - Optimal feeding regimen designed with nutritionist } \\
\text { - Follow up with necessary specialists arranged }\end{array}$ \\
\hline
\end{tabular}

\begin{tabular}{|c|c|}
\hline \multicolumn{2}{|r|}{ Outpatient } \\
\hline Emphasis on trends & $\begin{array}{l}\text { - Parents record } \mathrm{HR}, \mathrm{O}_{2} \text { sats, weight, enteral intake daily } \\
\text { - Call for red flags } \\
\text { - Weekly NP/PA calls } \\
\text { - Action plan based on findings } \\
\text { - Increase frequency of calls vs. clinic/ED visit } \\
\end{array}$ \\
\hline $\begin{array}{l}\text { Comprehensive Care } \\
\text { Coordination and } \\
\text { Continuity }\end{array}$ & $\begin{array}{l}\text { Direct, frequent communication between HMP and } \\
\text { outside providers } \\
\text { - Readmit to NP Cardiology service } \\
\text { - Single LPCH HMP Cardiologist }\end{array}$ \\
\hline
\end{tabular}

FIGURE 1. Key components of HMP. HMP, Home monitoring program; $N P / P A$, nurse practitioner/physician assistant; $C V I C U$, cardiovascular intensive care unit; $P C A R D$, primary cardiologist; $P M D$, primary care physician; $H R$, heart rate; $\mathrm{O}_{2}$ sats, oxygen saturations; $E D$, emergency department; $L P C H$, Lucile Packard Children's Hospital.

for this HMP cohort was $100 \%$. During this time period, a total of 60 patients underwent Norwood procedure at LPCH. Eleven patients died postoperatively before hospital discharge (range, 3-98 days), and 3 patients remained hospitalized until a successful Glenn surgery.

Table 1 displays the characteristics of the Norwood procedure patients in the HMP. The predominant lesion was hypoplastic left heart syndrome with mitral atresia and aortic atresia. All but 1 patient underwent a modified Norwood procedure with an RV-PA conduit. The other patient had a modified Blalock-Taussig shunt because of unusual PA anatomy that precluded placement of an RV-PA conduit. The median duration of interstage outpatient monitoring was 76 days (range, 17-221 days). The outlier, who was monitored for 221 days, had an interrupted inferior vena cava and was monitored until a Kawashima surgery. Of the 46 HMP patients, 25 were followed up solely by a community cardiologist because they lived far from LPCH, 15 were followed up internally at LPCH, and 6 regional patients were followed up by a community cardiologist in conjunction with the HMP cardiologist.

Nineteen HMP patients ( $41 \%$ ) had 27 readmissions during the interstage period. Five patients were re-admitted twice and 1 patient was re-admitted 4 times. The most common indications for admission were hypoxemia $(56 \%)$ and growth failure $(22 \%)$ (Table 2). Notably, no patient presented in extremis, in shock, or in impending respiratory failure. None had a cardiac arrest, renal failure, or stroke. Seven of the 19 patients remained inpatients until the Glenn surgery.

Of the 19 patients re-admitted, 17 patients had either major or minor interventions performed during the hospitalization, and only 2 patients were managed with observation
TABLE 1. Norwood HMP patient characteristics

\begin{tabular}{|c|c|}
\hline Demographics & No. of patients \\
\hline \multicolumn{2}{|l|}{ Sex } \\
\hline Male & $32(70 \%)$ \\
\hline Female & $14(30 \%)$ \\
\hline \multicolumn{2}{|l|}{ Diagnosis } \\
\hline HLHS & $37(80 \%)$ \\
\hline MA/AA & 16 \\
\hline MS/AS & 13 \\
\hline MS/AA & 5 \\
\hline MA/AS & 2 \\
\hline Critical AS & 1 \\
\hline AVSD & 3 \\
\hline DORV/MA/hypoplastic arch & 2 \\
\hline Tricuspid atresia/hypoplastic arch & 2 \\
\hline DILV & 1 \\
\hline Prenatal diagnosis & $35(76 \%)$ \\
\hline Age at Norwood procedure $(\mathrm{d})$ & $5(1-37)$ \\
\hline Weight at Norwood procedure $(\mathrm{kg})$ & $3.3(2.4-4.1)$ \\
\hline Age at Norwood discharge (d) & $37(15-95)$ \\
\hline Weight at Norwood discharge $(\mathrm{kg})$ & $4(2.6-4.9)$ \\
\hline Length of postoperative ICU stay (d) & $16.5(9-59)$ \\
\hline Length of postoperative hospital stay (d) & $31(12-83)$ \\
\hline Duration of HMP (d) & $76(17-221)$ \\
\hline Age at pre-Glenn surgery catheterization (d) & $98(64-172)$ \\
\hline Age at Glenn surgery (d) & $114(73-254)$ \\
\hline Weight at Glenn surgery $(\mathrm{kg})$ & $5.5(3.9-7.5)$ \\
\hline
\end{tabular}

only. Eight patients (17\% of the HMP cohort) underwent a major intervention, defined as unscheduled cardiac catheterization or surgery (Table 3). The most common indication for intervention was RV-PA conduit stenosis, which was addressed either with an early Glenn within several days after catheterization $(\mathrm{n}=3)$ or with conduit stenting $(\mathrm{n}=2)$. One other patient with conduit stenosis was scheduled for early Glenn 2 days after catheterization but developed profound acute hypoxemia on the night of catheterization and underwent an emergent modified Blalock-Taussig shunt. Aortic arch balloon angioplasty

TABLE 2. Indications for interstage re-admissions

\begin{tabular}{lc}
\hline \multicolumn{1}{c}{ Indication } & No. of patients \\
\hline Hypoxia & 15 \\
Growth failure & \\
$\quad$ Inadequate intake & 3 \\
Emesis & 3 \\
Other & \\
Respiratory distress & 2 \\
Tachyarrhythmia & 1 \\
Pericardial effusion & 1 \\
Positive blood culture & 1 \\
Hematochezia & 1 \\
\hline
\end{tabular}


TABLE 3. Interstage interventions

\begin{tabular}{lc}
\hline \multicolumn{1}{c}{ Major interventions } & No. of interventions \\
\hline Cardiac catheterization & 2 \\
RV-PA conduit stent & 1 \\
Aortic arch balloon angioplasty & 1 \\
Change in surgical plan & \\
Surgery & 3 \\
Early Glenn surgery & 1 \\
Shunt & No. of interventions \\
\hline \multicolumn{1}{c}{ Minor interventions } & 3 \\
\hline Supplemental oxygen & 3 \\
Intravenous therapy & 3 \\
Blood transfusion & 1 \\
Rehydration & 1 \\
Diuretics & 2 \\
Anti-arrhythmic & \\
Adjustment of enteral feeds & \\
\hline
\end{tabular}

$R V$ - $P A$, Right ventricle to pulmonary artery.

was performed in 1 patient. One patient with diaphragm eventration and an abnormal left lung had multiple distal PA stenoses, was deemed unsuitable for a Glenn surgery, and was scheduled for surgical pulmonary arterioplasty.

Nine patients ( $20 \%$ of the HMP cohort) underwent minor interventions during hospitalization including supplemental oxygen administration, blood transfusion, intravenous fluid or medications (diuretics, antibiotics, anti-arrhythmics), or adjustment of enteral feedings (Table 3). Some patients had more than 1 readmission and had 1 minor intervention performed each time. Two patients required observation only, 1 patient for hematochezia and 1 patient with influenza B.

All HMP patients survived to second stage surgical palliation. Forty-five patients $(98 \%)$ underwent successful bidirectional Glenn surgery. The patient with multiple distal pulmonary artery stenoses who was unsuitable for a Glenn surgery died after surgical pulmonary arterioplasty. There were no perioperative Glenn deaths. There were 4 late deaths after a Glenn surgery: 1 from a brain tumor, 1 from heart failure, 1 with heart failure and presumed arrhythmia, and 1 unexplained sudden death at home. One former HMP patient underwent cardiac transplantation 7 months after the Glenn surgery. Twenty patients successfully completed Fontan palliation, which typically is performed at 3 years of age using an extracardiac conduit in our institution. ${ }^{19}$

In addition to the primary aim of improved interstage survival, the high level of HMP surveillance allowed for a change in feeding management in our Norwood procedure patients. In the absence of safety data, before the HMP, patients who could not establish growth with oral feedings alone underwent gastrostomy tube placement. Concurrent to the initiation of the HMP, we began discharging patients with nasogastric (NG) tubes in combination with oral feeds, unless patients were unable to protect their airway from

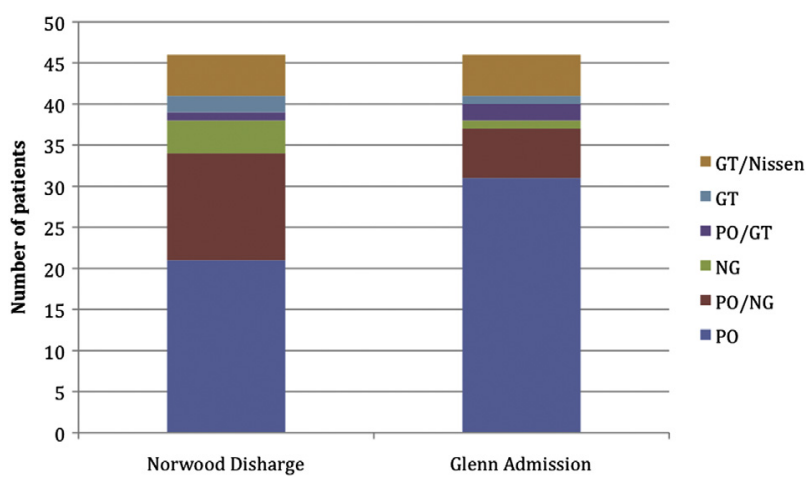

FIGURE 2. Route of enteral feeding for HMP patients. $G T, \mathrm{G}$ tube; $P O$, by mouth; $N G$, nasogastric.

direct aspiration or reflux (Figure 2). During the study period in 2007, a retrospective review of laparoscopic gastrostomy procedures in Norwood patients from our institution showed some morbidity, which substantiated the new management strategy. ${ }^{20}$ All patients were assessed initially for oral feeding safety at the bedside by an occupational therapist once NG feeding tolerance was established early after the Norwood procedure. If the occupational therapist had concerns, or if the patient had no audible voice, then further functional evaluation occurred with a modified barium swallow. Patients with aspiration by functional evaluation underwent gastrostomy tube placement. Direct laryngoscopy was used in some cases to assess vocal cord function but was not used routinely. Parents were trained using teach-back methods for all Norwood care including NG placement, performing multiple directly supervised tube placements, and using home equipment before discharge.

At discharge after the Norwood procedure, 17 patients (37\% of the HMP cohort) required NG tube feeding to attain their caloric intake goal (Figure 2). There were no adverse events associated with NG feeding. Notably, during the interstage period, most patients had improved oral intake. Ten patients who were receiving tube feeds at the time of Norwood procedure discharge transitioned to full oral feeds by the time they were admitted for their Glenn surgery. Only 8 patients (17\% of the HMP cohort) required a gastrostomy tube $(\mathrm{n}=3)$ or a gastrostomy tube/Nissen fundoplication $(\mathrm{n}=5)$. Of these, 7 infants had vocal cord paresis or paralysis documented by direct laryngoscopy and were believed to be at risk of aspiration.

Active attention to interstage growth was an important part of the HMP. The median weight of the HMP cohort at Glenn surgery was $5.5 \mathrm{~kg}$ (range, $3.9-7.5 \mathrm{~kg}$ ) at a median age of 114 days (range, 73-254 days).

\section{DISCUSSION}

In 2005, an interstage HMP was established for Norwood procedure patients. Through the first 5 years of the HMP, 
interstage survival was $100 \%$. Forty-one percent of patients were re-admitted during the interstage period, but none presented with cardiac arrest, shock, impending respiratory failure, renal failure, or stroke. This is a substantial reduction in interstage mortality and morbidity compared with prior single-center and multicenter reports. ${ }^{11,13-15,21,22}$ Ghanayem et $\mathrm{al}^{16}$ previously showed a survival benefit with HMP in Norwood procedure patients with a modified Blalock-Taussig shunt. Our results also confirm that home monitoring reduces interstage mortality in patients undergoing a modified Norwood procedure with an RV-PA conduit.

The goal of the HMP is to identify physiologic disturbances before decompensation and to provide an early warning system to allow for timely interventions. In our cohort, this approach successfully prevented major decompensations: there were no deaths, cardiac arrests, or respiratory failures. However, $37 \%$ of patients required interstage interventions, which were triggered by concerns raised by the HMP. Seventeen percent required major interventions, defined as unscheduled interventional catheterization or surgery. The percentage of patients requiring such intervention was remarkably close to previously reported interstage mortality rates. The patients who underwent major interventions may represent near-miss deaths; if so, early identification of anatomic or physiologic abnormalities via the HMP has reduced mortality.

Among this fragile population, it also was notable that many patients were re-admitted during the interstage period; however, only 2 patients were admitted just for observation. This suggests that admissions were not prompted simply by heightened parental anxiety or overly conservative practice by the HMP team. Rather, the availability of oxygen saturation and growth data trends often substantiated parental observations and enhanced decision making by the clinical team.

It is not clear from these findings whether improved survival is the result of closer assessment of physiologic variables, intensified care coordination, or a combination of both of these factors. The HMP is a complex care model that facilitates communication between the family and all clinical providers. A team of multidisciplinary providers works together closely to care for these infants at home. In our experience, because of the surveillance calls, there was a lower threshold for contact between parents and the HMP NPs. There also was tighter coordination between community cardiologists and the surgical site and a smoother transition from inpatient to outpatient care. When issues arise, the HMP is an additional resource for the family or emergency providers at times when a local cardiologist or pediatrician may be unavailable. The Norwood procedure HMP is a model that has far-reaching implications in the care of children with chronic diseases to ensure multidisciplinary care coordination outside the hospital across pediatric specialties.
An intact atrial septum, older age at surgery, perioperative arrhythmias, airway complications, and decreased ventricular function at hospital discharge have been reported as risk factors for interstage death in Norwood procedure patients. ${ }^{21,22}$ In our cohort, specific physiologic risk factors for re-admission or intervention could not be defined. However, in response to lessons learned from re-admissions during the first 2 years, a number of changes were made in the HMP. Based on several patients needing urgent unplanned catheterizations early in the experience as a result of cyanosis from conduit stenosis, the HMP tried to schedule the pre-Glenn surgery catheterization at the patient's 3-month birthday (regardless of patient age at Norwood procedure discharge). Although we anticipated some variability, to our surprise, all patients except the patient with the diaphragm eventration have had acceptably low pulmonary vascular resistance by 3 months of age to be eligible for Glenn surgery. Thus, since 2006, all patients have been scheduled for elective catheterization at 3 months of age. In response to gaps in care in the transition home, the HMP began setting up the pre-Glenn surgery catheterization date before Norwood procedure hospital discharge. After the catheterization, the timing of the Glenn surgery then is determined based on the patient's clinical status. If the patient persistently has oxygen saturation levels less than $70 \%$ or has plateaued in growth, then the patient is put forward at that time for surgery. Otherwise, the patient is continued in the HMP and scheduled at about 4 months of age or when the cardiologist and surgeon think surgery is indicated clinically.

The programmatic change in timing of the elective catheterization may have contributed to improved interstage survival by decreasing the duration of the interstage period. Before the HMP, from 2002 to 2005, the mean age at preGlenn surgery catheterization for Norwood procedure patients was 126 days and the mean age at bidirectional Glenn surgery was 151 days. ${ }^{10}$ From 2005 to 2010 , the mean age at catheterization was 99 days and the mean age at Glenn surgery was 118 days. Anecdotally, no increase in perioperative Glenn surgery morbidity has been noted, although this was not studied formally in this cohort.

Early on, there was a trend toward more re-admissions in patients who lived farther than an hour away from LPCH and in patients whose families were not native English speakers. Surveillance was heightened for the remote patients by more direct contact by the HMP team with the local pediatrician as well as the community cardiologist. Initially, we thought it would be difficult to make this program work for remote patients, but over time it seems that these patients may be a subset for whom the care coordination piece has been especially helpful, perhaps because the family is more dependent on the local primary care provider and the HMP team is an additional cardiology resource. For the non-English speaking families, the program was 
adjusted to have the family assigned to an NP fluent in their language (which was predominantly Spanish in our population).

Although the primary aim of the HMP was to improve survival, a secondary benefit was that the high level of surveillance allowed for a change in feeding management. With initiation of the HMP, there was a shift away from gastrostomy tubes toward NG tubes for patients who could not maintain weight gain with oral feedings alone. In our experience, NG feeding has been safe and effective. Not only were there no adverse events associated with NG tubes, but additionally this practice allowed many infants to transition to full oral feeds before the Glenn surgery. Currently, in our practice, gastrostomy tubes, usually with Nissen fundoplication, are reserved for the small minority of patients who cannot protect their airway based on functional evaluation with a modified barium swallow. Active attention to interstage growth is an important part of the HMP.

In summary, interstage home monitoring has improved survival of modified Norwood patients. However, approximately $40 \%$ must be re-admitted to the hospital during the interstage period. The ultimate goal of the HMP will be to maintain high interstage survival with shorter inpatient hospitalizations and less interstage re-admissions. Efforts currently are underway in the multicenter National Pediatric Cardiology Quality Improvement Collaborative to refine predictors of risk for individual patients and to identify specific practices associated with improved interstage survival and lower admission rates. ${ }^{23-25}$

We gratefully acknowledge the assistance of Nancy Ghanayem, George Hoffman, and Nancy Rudd from the Children's Hospital of Wisconsin and Jana Norris from LPCH in the initial implementation of our HMP. We also acknowledge the following clinicians who formed the HMP team that achieved this improved survival: Jana Norris, Jennifer Bond, Kiersten Wells, Raji Koppolu, Rosalie Simon, Kaberi Mozumder, Carley Goldberg, Danielle Toner, Tara Drake, Laura Montafi, Sandy Staveski, Elizabeth Price, Guadalupe Tovar, and Lisa Schultz.

\section{References}

1. Bove EL, Lloyd TR. Staged reconstruction for hypoplastic left heart syndrome. Contemporary results. Ann Surg. 1996;224:387-94.

2. Forbess JM, Cook N, Roth SJ, Serraf A, Mayer JE Jr, Jonas RA. Ten-year institutional experience with palliative surgery for hypoplastic left heart syndrome. Risk factors related to stage I mortality. Circulation. 1995;92:II262-6.

3. Mahle WT, Spray TL, Wernovsky G, Gaynor JW, Clark BJ 3rd. Survival after reconstructive surgery for hypoplastic left heart syndrome: a 15-year experience from a single institution. Circulation. 2000;102:III136-41.

4. Tweddell JS, Hoffman GM, Mussatto KA, Fedderly RT, Berger S, Jaquiss RD, et al. Improved survival of patients undergoing palliation of hypoplastic left heart syndrome: lessons learned from 115 consecutive patients. Circulation. 2002;106: I82-9.

5. Bartram U, Grunenfelder J, Van Praagh R. Causes of death after the modified Norwood procedure: a study of 122 postmortem cases. Ann Thorac Surg. 1997;64:1795-802.
6. Mahle WT, Spray TL, Gaynor JW, Clark BJ III. Unexpected death after reconstructive surgery for hypoplastic left heart syndrome. Ann Thorac Surg. 2001; $71: 61-5$.

7. Wright GE, Crowley DC, Charpie JR, Ohye RG, Bove EL, Kulik TJ. High systemic vascular resistance and sudden cardiovascular collapse in recovering Norwood patients. Ann Thorac Surg. 2004;77:48-52.

8. Pizarro C, Mroczek T, Malec E, Norwood WI. Right ventricle to pulmonary artery conduit reduces interim mortality after stage 1 Norwood for hypoplastic left heart syndrome. Ann Thorac Surg. 2004;78:1959-63.

9. Cua CL, Thiagarajan RR, Taeed R, Hoffman TM, Lai L, Hayes J, et al. Improved interstage mortality with the modified Norwood procedure: a meta-analysis. Ann Thorac Surg. 2005;80:44-9.

10. Reinhartz O, Reddy VM, Petrossian E, MacDonald M, Lamberti JJ, Roth SJ, et al. Homograft valved right ventricle to pulmonary artery conduit as a modification of the Norwood procedure. Circulation. 2006;114:I594-9.

11. Ballweg JA, Dominguez TE, Ravishankar C, Kreutzer J, Marino BS, Bird GL, et al. A contemporary comparison of the effect of shunt type in hypoplastic left heart syndrome on the hemodynamics and outcome at stage 2 reconstruction. J Thorac Cardiovasc Surg. 2007;134:297-303.

12. Tabbutt S, Dominguez TE, Ravishankar C, Marino BS, Gruber PJ, Wernovsky G, et al. Outcomes after the stage I reconstruction comparing the right ventricular to pulmonary artery conduit with the modified Blalock Taussig shunt. Ann Thorac Surg. 2005;80:1582-90.

13. Lai L, Laussen PC, Cua CL, Wessel DL, Costello JM, del Nido PJ, et al Outcomes after bidirectional Glenn operation: Blalock-Taussig shunt versus right ventricle-to-pulmonary artery conduit. Ann Thorac Surg. 2007;83: 1768-73.

14. Graham EM, Zyblewski SC, Phillips JW, Shirali GS, Bradley SM, Forbus GA, et al. Comparison of Norwood shunt types: do the outcomes differ 6 years later? Ann Thorac Surg. 2010;90:31-5.

15. Ohye RG, Sleeper LA, Mahony L, Newburger JW, Pearson GD, Lu M, et al. Comparison of shunt types in the Norwood procedure for single-ventricle lesions. N Engl J Med. 2010;362:1980-92.

16. Ghanayem NS, Hoffman GM, Mussatto KA, Cava JR, Frommelt PC, Rudd NA, et al. Home surveillance program prevents interstage mortality after the Norwood procedure. J Thorac Cardiovasc Surg. 2003;126:1367-77.

17. Ghanayem NS, Cava JR, Jaquiss RD, Tweddell JS. Home monitoring of infants after stage one palliation for hypoplastic left heart syndrome. Semin Thorac Cardiovasc Surg Pediatr Cardiac Surg Ann. 2004;7:32-8.

18. Ghanayem NS, Tweddell JS, Hoffman GM, Mussatto K, Jaquiss RD. Optimal timing of the second stage of palliation for hypoplastic left heart syndrome facilitated through home monitoring, and the results of early cavopulmonary anastomosis. Cardiol Young. 2006;16(suppl 1):61-6.

19. Petrossian E, Reddy VM, Collins KK, Culbertson CB, MacDonald MJ Lamberti JJ, et al. The extracardiac conduit Fontan operation using minimal approach extracorporeal circulation: early and midterm outcomes. J Thorac Cardiovasc Surgery. 2006;132:1054-63.

20. Slater B, Rangel S, Ramamoorthy C, Abrajano C, Albanese CT. Outcomes after laparoscopic surgery in neonates with hypoplastic heart left heart syndrome J Pediatr Surg. 2007;42:1118-21.

21. Hehir DA, Dominguez TE, Ballweg JA, Ravishankar C, Marino BS, Bird GL, et al. Risk factors for interstage death after stage 1 reconstruction of hypoplastic left heart syndrome and variants. J Thorac Cardiovasc Surg. 2008;136:94-9, e91-3.

22. Simsic JM, Bradley SM, Stroud MR, Atz AM. Risk factors for interstage death after the Norwood procedure. Pediatr Cardiol. 2005;26:400-3.

23. Schidlow DN, Anderson JB, Klitzner TS, Beekman RH 3rd, Jenkins KJ, Kugler JD, et al. Variation in interstage outpatient care after the Norwood procedure: a report from the joint council on congenital heart disease national quality improvement collaborative. Congenit Heart Dis. 2011;6:98-107.

24. Menon SC, McCandless RT, Mack GK, Lambert LM, McFadden M, Williams RV, et al. Clinical outcomes and resource use for infants with hypoplastic left heart syndrome during bidirectional Glenn: summary from the joint council for congenital heart disease national pediatric cardiology quality improvement collaborative registry. Pediatr Cardiol. 2013;34:143-8.

25. Hehir DA, Cooper DS, Walters EM, Ghanayem NS. Feeding, growth, nutrition, and optimal interstage surveillance for infants with hypoplastic left heart syndrome. Cardiol Young. 2011;21(suppl 2):59-64. 
Parent-NP call

reveals problem

NP notifies HMP

cardiologist

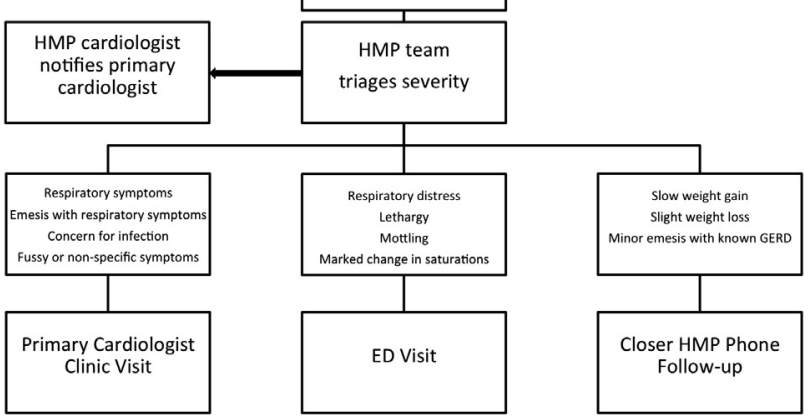

FIGURE E1. When there were clinical concerns from either the parent or the NP, an action plan was created. Depending on the severity of the concern, the patient was seen by a clinician or the HMP call frequency was increased. Overall, symptoms were presumed to be cardiac in nature until proven otherwise, and there was a low threshold to have the patient seen whenever any issues arose throughout the interstage period. Patients were sent to their primary cardiologist's office for most problems, but there were many effective variations to this algorithm. In some cases, the primary care provider was involved integrally, and in other scenarios the majority of communication occurred between the HMP team and the primary cardiologist. The emphasis was always on very close, direct communication between the family, the HMP team, the primary cardiologist, and the pediatrician. The HMP NPs documented all calls in the LPCH electronic medical record, so concerns and plans were accessible to all HMP team members and to on-call cardiology fellows. NP, Nurse practitioner; $H M P$, home monitoring program; GERD, gastroesophageal reflux disease; $E D$, emergency department. 